\title{
A tradução e a falha ${ }^{1}$
}

Regina Helena de Oliveira Machado*

O não à tradução é interior à força de tradução $e$ é isso que faz com que a tradução seja um combate incessante. ANTOINE BERMAN Seminário La traduction et la défaillance, 1986

Sorriso largo, grandes mãos irrequietas, dedos intermináveis, Antoine Berman nos acolhia, ano após ano, para um percurso sinuoso: o de seu pensamento se fazendo, ali, diante de nós. Como se pelas mãos e passo a passo, ele nos conduzisse ao longo do caminho que ele mesmo percorria através do estudo da tradução/de traduções; e de sua experiência - em direção à "pura meta da tradução".

O primeiro seminário ao qual assisti se intitulava La traduction et la défaillance, que eu traduzi por "A tradução e a falha".

Sobre a escolha da palavra "falha" para traduzir do francês a palavra défaillance. Ela tem uma polissemia que autoriza leituras múltiplas: pode significar defeito, estado de algo que falta, que falha, que é incompleto, errado ou insuficiente.

Pode significar também desfalecimento, uma ausência (ou inconsciência) precedendo a emergência de algo que estava adormecido ou oculto.

\footnotetext{
${ }^{1}$ Este texto foi escrito a partir de notas tomadas durante os seminários de Antoine Berman, no Colégio Internacional de Filosofia de Paris (1984-1989), aos quais assisti a partir de 1986. Refiro-me principalmente ao texto "La traduction et la lettre ou l'auberge du lointain", in Les tours de Babel, collectif, ed. T.E.R., Paris 1985, que condensa uma grande parte dos seminários. Tradução brasileira: A tradução e a letra ou o albergue do longínquo, tradução coletiva de Marie-Hélène Catherine Torres, Mauri Furlan, Andréia Guerini, ed. 7Letras, Rio de Janeiro, 2007. Indico, no corpo do texto, unicamente as páginas do livro.

* Tradutora. Professora aposentada de língua e literatura (opção explicação de texto e tradução) para os alunos preparando a Agregação na Ecole Normal Supérieure de Fontenay aux Roses - hoje em Lyon - e no CNED (Centre National d'Enseignement à Distance), France.
} 
Num outro sentido, dito literário, significa "falhar", "faltar ao dever".

Como não pensar aqui na frase de Antoine Berman "toute traduction est fautive", que pode também ser traduzida por "toda tradução é culpada"? Alusão à dimensão transcendente - dever, lei, ética - no horizonte da tradução?

Uso o termo "falha" para designar, tal qual o negativo de uma fotografia, um erro, defeito. Um espaço em branco, que pode ser revelação: brecha por onde escapa a verdade da tradução, seu possível e sua "lei": o que faz dela "o albergue do longínquo". Espaço intersticial, em que o Estrangeiro que é o original é acolhido como Estrangeiro pela tradução.

Antoine Berman indica que o horizonte de sua reflexão é uma "tradutologia": estudo, análise, ciência, um "pensamento-da-tradução", que, "sem ser de modo algum uma 'filosofia da tradução' deve necessariamente enraizar-se no pensamento filosófico" [...] "a pura meta da tradução é ética, poética, filosófica".2

É no espaço de um advir, de uma meta (visée), que se situa a reflexão de Berman. Não se trata, portanto, de um pensamento totalizador, de uma ciência a transmitir. Trata-se de um pensamento em movimento, com uma história, uma tradição e uma meta a ser atingida.

É contra a expressão consagrada (lugar-comum) "tradutor-traidor" que se levanta a obra de Antoine Berman. Seu caminho é o estudo e análise de traduções, para extrair, das diversas práticas históricas do traduzir, a noção de "verdade da tradução".

Dada a complexidade de seu pensamento e de sua obra, de suas ramificações abundantes, muitas vezes desconcertantes, o presente texto se limita a dois eixos de reflexão que pretendo destacar:

1) Um primeiro nível que consiste em dar destaque ao que há de positivo, enquanto horizonte, no trabalho de Antoine Berman.

2) Um segundo nível, negativo, que é o da análise crítica das traduções (Antoine Berman criou o substantivo "analítica" para designar esse trabalho).

Esses dois níveis são intrinsecamente ligados, pois um (o da analítica das traduções) deve dar lugar ao outro (horizonte ou meta da "tradução ética, poética, filosófica").

2 Tradução brasileira, op.cit., p. 19. 
A separação que opero é, portanto, artificial, efêmera, uma estratégia de leitura. Não evidente, pois, como veremos, o espaço próprio da tradução é definido através da passagem necessária por seu negativo. Ao dizer o que é uma tradução que tem por meta a fidelidade à obra original, ele diz ao mesmo tempo o que ela não é.

Há aqui uma injunção, uma lei intrínseca à tradução no sentido em que esta é transmissão, relação ao outro. E, mesmo se a tradução-adaptação aparece como recusa dessa relação, ela não está menos sujeita a uma lei. Ela tem uma dívida em relação à obra original. E esta, a obra, se revolta contra toda tentativa de apropriação. Algo resiste, e falha, na tentativa de apropriação.

Existe um elo entre a tradução, a interpretação, a leitura (e, portanto, o comentário). A tradução e a interpretação são uma única e mesma coisa. Não no sentido de uma "interpretação livre", pois ela está ligada ao original cuja textualidade reclama o que lhe é devido.

A interpretação/tradução, neste contexto, é regida pela lei entendida como: fidelidade à letra do texto e fidelidade à obra, outra cultura, outro texto; como "memória fiel" à tradição de transmissão.

A noção de interpretação tem a marca dessa lei, a tradução é transmissão, onde o que é transmitido "conserva seu caráter próprio" quando traduzido.

A tal ponto que, segundo essa exigência e essa meta, a obra traduzida pode operar mudanças na língua de tradução (introduzindo nela estranhezas, novas formas gramaticais e sintáticas, neologismos... enriquecendo-a enfim): quanto mais a língua de tradução acolhe o original e sua linguagem, mais ela muda. Esse movimento é o que faz a historicidade da tradução (seminário, 1986).

A tradução é experiência e reflexão:

Experiência das obras e do ser-obra, das línguas e do ser-língua. [...] Em outros termos, no ato de traduzir está presente um certo saber, um saber sui generis. [...] Chamo a articulação consciente da experiência da tradução distinta de todo saber objetivante e exterior a ela (assim como elaboram a linguística, a literatura comparada, a poética), de tradutologia (2007, p. 18). 
A tradutologia: a reflexão da tradução sobre si mesma a partir de sua natureza de experiência. (p.19)

Horizonte e projeto do tradutor-pensador - paixão da tradução

\begin{abstract}
Apareceu-me... que a tradução se movia num espaço complexo, entrecruzado de "línguas", um espaço que poderia ser o verdadeiro espaço de Babel, um espaço que não é somente o da simples multiplicidade das "línguas", no sentido comum das línguas faladas pelos homens nesta terra. Encontramos obras escritas - se é que se pode dizer assim - em duas línguas: inglês e latim (Milton), espanhol e guarani (Roa Bastos); em línguas e dialetos (Gadda ${ }^{3}$, Guimarães Rosa); em diversas camadas e estratos de línguas, a cavalo entre a fala e a escrita, entre a língua vernacular e a língua culta; obras escritas numa língua, mas no horizonte de uma outra língua, e mesmo de várias outras; obras escritas após terem sido habitadas por línguas, ou a partir de traduções...

Tal é o espaço emaranhado de línguas, no qual está situada nossa relação à própria língua (p. 17, Seminário sobre "A língua materna", 1984, inédito, minha tradução) ${ }^{4}$.
\end{abstract}

Estranho espaço "próprio" esse feito de outros espaços, cruzamento e mistura de línguas, mestiçagem. Por camadas de leituras de outras obras, de traduções, de experiências (saber e conhecimento do tradutor, sua "cultura").

Por isso a tradutologia não pode ser uma teoria da tradução, “... ao contrário, ela mostraria antes que tal teoria não pode existir, pois o espaço da tradução é babélico, isto é, recusa qualquer forma de totalização" (2007, p. 21).

Nem teoria, nem disciplina, nem metodologia, mas "... um modo de ensino que, grosso modo, é o da filosofia e da psicanálise [...] um espaço [...] de natureza intersticial" (p. 24). "Não existe $a$ tradução (como postula a teoria da tradução) mas uma multiplicidade rica e desconcertante escapando a qualquer tipologia, existem as traduções, o espaço das traduções, que cobre o espaço do que há em toda parte, em todo lugar, para-traduzir (2007, p. 24)."

E para designar o lugar de onde fala, Antoine Berman diz:

\footnotetext{
${ }^{3}$ Carlo Emilio Gadda, escritor italiano, 1893-1973.

4 Seminário sobre a "Língua materna". A "própria língua" designa aqui a língua de tradução que é supostamente a "língua materna" do tradutor. Entre os anos 80 e hoje uma mudança fundamental vem acontecendo na França. Vemos surgir hoje traduções realizadas inteiramente por tradutores cuja língua materna é a língua do original, ou por binômios de tradutores: um cuja língua materna é a língua do original, e outro cuja língua materna é a língua de tradução.
} 
Eu me questiono sobre o espaço da tradução a partir da experiência da tradução chamada muito impropriamente "literária" (se trataria antes da tradução das obras, além de qualquer distinção de genêro ${ }^{5}$, das obras profanas, diria Benjamim em oposição aos textos sagrados) e a partir da experiência da filosofia - na medida em que minha experiência da filosofia é aquela, moderna, de um pensamento sempre-já preso nas redes de tradução (e também na medida em que, logo falarei a respeito, as próprias obras, na Idade Moderna, concebem-se como tradução) (p. 21).

Mas antes, é necessário passar pelo que existe. Pelo contrário do que se vai buscar: as traduções existentes, o estudo e a análise das diferentes formas de deformação e de destruição das obras originais nas traduções. Antoine criou o substantivo "analítica" para designar esse trabalho "rigoroso e sistemático" de análise das falhas de tradução. "O espaço da tradução é aquele da inevitável fragilidade. O defeito de tradução é inerente à tradução" (Nota 34, p. 66 de "La traduction et la lettre"; tradução brasileira, nota 16, p. 134).

A deformação é o que impede a tradução de atingir "a sua pura meta", que é a realização da tradição, "um mundo onde tudo é transmitido" e onde o que é transmitido conserva seu caráter próprio em outra língua ou cultura. Na transmissão as obras aparecem de uma outra maneira. Em sua irredutível alteridade. Mas esta só aparece nos interstícios da tradução tornada obra.

Deformação é o outro nome da não-tradução. Esta é resistência à tradução. As grandes traduções, tornadas obras, são aquelas que atravessam a barreira do NÃO à tradução.

Resistir, enfrentar esse não é algo muito difícil; as dificuldades são múltiplas e de níveis diferentes: a de compreender a outra cultura, a alteridade da obra estrangeira, sua estranheza; elas são culturais, psicológicas, linguísticas, literárias.

Mas "quando examinamos cada uma dessas dificuldades percebemos que elas não são insuperáveis", pois "existe uma pulsão de tradução extremamente forte; é essa pulsão que faz com que existam grandes traduções".

\footnotetext{
${ }^{5}$ Salvo a distinção entre tradutologia e tradútica, por referência às traduções técnicas, comerciais, publicitárias, e todas às que tocam à informática no mundo atual.
} 
A paixão da tradução tem uma força inversa igual à força de nãotradução.

\section{Combate contra a não-tradução}

Para alcançar o espaço singular da tradução, "sua essência", sua "verdade", "simultaneamente ética, poética e pensante [...] é necessário operar um trabalho de destruição...".

\footnotetext{
Entretanto, essa destruição - se ela não quiser ser uma simples operação ideológica ou teórica - deve ser precedida de uma análise do que há por destruir. A esse trabalho, que é simultaneamente análise e destruição [...], chamaremos analítica da tradução. [...]

A analítica, que é por essência negativa, abre por sua vez uma reflexão (positiva) sobre a dimensão ética, poética e pensante do traduzir. Essa tripla dimensão é o inverso exato da tripla dimensão da figura tradicional da tradução. À tradução etnocêntrica se opõe a tradução ética. À tradução hipertextual, a tradução poética.

À tradução platônica, ou platonizante, a tradução "pensante" (2007, p. 2627).
}

A análise da falha e da destruição da obra original, pela tradução, conduz assim a uma análise da sistematicidade da transformação: traduçãoadaptação, ou tradução etnocêntrica.

Face à concepção antiga e persistente da tradução como adaptação, se ergue a meta de uma tradução ética como fidelidade à letra da obra e fidelidade ao outro.

E em que consiste a tradução da letra do texto? Uma tradução que que teria por horizonte a fidelidade à obra original e sua verdade?

A análise dos diversos modos de transformação das obras originais pela tradução deixa ver, por contraste, o que é a letra de um texto que em verdade não é UMA, mas constituída de "todas as dimensões às quais se ataca o sistema de deformação" (em francês, p. 81, em português, p. 62, tradução revista por mim). De fato, o sistema de destruição "se ataca" à letra do texto original, e não apenas o "atinge" (cf. tradução brasileira; esta atenua a violência da frase. Grifo meu). 


\title{
O sistema de deformação e de destruição das obras originais
}

Vou simplesmente enumerar aqui algumas características desse tipo de tradução que uma leitura atenta não terá dificuldade em reconhecer.

\section{A tradução etnocêntrica ou hipertextual}

Etnocêntrica significará aqui: a que traz tudo à sua própria cultura, às suas normas e valores, e considera o que está situado fora dela - o Estrangeiro como negativo ou apenas bom para ser anexado, adaptado, para aumentar a riqueza dessa cultura.

Hipertextual reenvia a todo texto gerado por imitação, paródia, pastiche, adaptação, plágio, ou qualquer outra espécie de transformação formal, a partir de um texto já existente (p. 28).

Fazem parte desse tipo de deformação o sincretismo e a adaptação: a anexação, pela tradução das singularidades da obra traduzida. Essa anexação só pode ser anexação do sentido, separado da letra do texto. Separação entre "corpo" e "alma", "sensível e inteligível".

Nessa etapa, o exemplo mais significativo que nos dá Antoine Berman é a tradução da Bíblia por São Jerônimo, oficialmente reconhecida pela Igreja Católica, e dita "composição em latim" em certos artigos consagrados a esse texto ${ }^{6}$.

Esse exemplo de anexação constitui um importante episódio da história das traduções, pois é a versão que, oficializada pela Igreja, dá SEU sentido ao texto hebraico e o transforma para todo o Ocidente e todas as gerações posteriores (2007, p. 31).

\begin{abstract}
A tradução não se importa com a letra morta: ela vai, para captá-lo ao espírito vivo, ao sentido. Enquanto a tradição judaica desconfiava da tradução, é realmente o imperativo categórico do cristianismo a tradução do Livro em todas as línguas, a fim de que o sopro vivificante do Espírito atinja todas as nações (Atos dos Apóstolos, 2,4) (p. 31).
\end{abstract}

Incorporação do sentido e ocultação da letra

Trata-se da incorporação do sentido de uma obra, pela outra língua considerada como "superior" (a língua de tradução), da anexação e

\footnotetext{
${ }^{6}$ A Vulgata é a versão latina, traduzida inicialmente por Jerônimo de Stridon no fim do século IV, a partir do texto hebreu do Antigo Testamento e do texto grego do Novo Testamento.
} 
"aclimatação" da obra estrangeira, de tal maneira que ela apareça como "fruto" da língua de tradução.

Da tradução etnocêntrica, derivam princípios que podemos reconhecer em muitas traduções, ainda hoje:

- A obra estrangeira não deve parecer uma tradução, ela não deve "ter cheiro" de tradução, deve dar a impressão de que o autor teria escrito na língua de tradução.

- A tradução deve, portanto, se fazer esquecer, ela deve ser "transparente" (como o tradutor).

- Todo traço da língua de origem deve desaparecer. E não deve chocar com suas "estranhezas lexicais ou gramaticais".

- A tradução deve ser escrita numa língua normativa, e totalizante.

Ora, nenhuma obra literária que merece esse estatuto é normativa, escrava das normas linguísticas do seu tempo. Assim, a tradução-anexação é ainda "mais normativa que a de uma obra escrita diretamente na língua de tradução" (2007, p. 33).

\section{O sistema das tendências deformadoras à obra nas traduções}

Na sua Analítica da tradução e sistemática da deformação (2007, p. 45), analisando obras traduzidas, Antoine Berman mostra como essas tendências formam um sistema e "concernem toda tradução, qualquer que seja a língua, ao menos no espaço ocidental" (p. 48).

Elas se opõem à meta de fidelidade à obra estrangeira, à tradução ética, como "albergue do longínquo".

\section{Racionalização}

Esta tendência se aplica sobretudo à sintaxe da obra original, ao seu ritmo, obedecendo a uma ideia preconcebida de uma certa ordem do discurso. Ela recompõe, ordena, generaliza, apaga e oculta a arborescência sintática de toda obra, sua polifonia, o emaranhado (matagal) que constitui seu tecido, e torna abstrato o concreto do texto.

\section{Clarificação}

Esta acompanha a racionalização e compreende certas formas de definição do que no original aparece como indefinido, e toda tradução tem uma 
dimensão de explicitação: "ela é inerente ao ato de traduzir". No entanto, isso pode significar duas coisas bem diferentes:

Num sentido negativo: "a explicação visa a tornar 'claro' o que não o é e não quer sê-lo no original. A passagem da polissemia à monossemia é um modo de clarificação. A tradução parafrásica ou explicativa, um outro" (p. 51). Essa tendência vai de par com a do "alongamento".

Num sentido positivo: "A explicitação pode ser a manifestação de algo que não é aparente, mas oculto ou reprimido no original. A tradução por seu próprio movimento revela esse elemento" (p. 51).

\section{Alongamento}

A consequência dessas duas primeiras tendências é que toda tradução tende a ser mais longa que o original. $\mathrm{O}$ alongamento consiste em "explicitar", por acréscimo, o que está "dobrado", ou implícito no original. O acréscimo não acrescenta nada, senão que ele tende a tornar "vazio" o que na obra é "informe", sua obscuridade ou falha constitutiva.

Por exemplo, na obra de Clarice Lispector: quando a necessidade de dizer, de falar, esbarra com os limites da linguagem, e então a escrita parece empurrar e estraçalhar a língua em que se forma, e são múltiplos os momentos em que sua linguagem beira abismos, tornando-se atropelos da língua, contorções gramaticais, construções extravagantes.

\section{Enobrecimento}

... é apenas uma re-escritura, um exercício de estilo 'a partir' (e às custas) do original" (p. 52).

Transformação da linguagem própria à obra por uma retórica do "belo discurso", uma "poetização", ou ainda transformação de frases comuns em "elegantes" (cf. As belas elegantes, na tradição francesa).

Esse procedimento tende a extrair do texto traduzido sua dimensão oral. A tornar "belo" o que decorre da linguagem popular, ou ao contrário, pelo procedimento inverso, a vulgarizar o que no original é "popular", a transformar a "gíria" em grosseria, reescrever ou "corrigir" tudo o que provém de um falar rural ou de diferentes camadas sociais urbanas. 
Empobrecimento qualitativo

... a substituição dos termos, expressões, modos de falar que não têm nem sua riqueza sonora, nem sua riqueza significante... (2007, p. 53).

Empobrecimento quantitativo

Perda da abundância lexical da obra.

A grande prosa romanesca ou epistolar é "abundante" (p. 54).

Redução da massa significante da obra e da arborescência de seu tecido lexical pela homogeneização, resultado das tendências enumeradas acima.

Ela consiste em unificar em todos os planos o tecido do original, embora este seja originariamente heterogêneo (p. 55).

Destruição dos ritmos

Esta tendência é global - todo outro procedimento de deformação é também destruição do ritmo das obras. Ela se ataca sobretudo à sintaxe e à pontuação dos textos, sua respiração. Como as outras tendências deformadoras, é destruição da sistemacidade da obra original.

Contrariamente ao que se entende em geral, o ritmo não é próprio unicamente à poesia. A prosa também é ritmo. Essa questão foi amplamente tratada, particularmente por H. Meschonnic, em Pour la poétique I, II, III; Critique du rythme, e em toda sua obra.

Antoine Berman cita abundantemente H. Meschonnic, em todos os seus trabalhos: "A prosa revela melhor que o verso a linguagem poética."7

Destruição das expressões e proverbiais e locuções vernaculares

Toda grande prosa entretém uma relação particular com a linguagem singular de certos grupos, regiões ou camadas sociais. Um grande emaranhado de línguas, idiotismos e assim camadas de leituras e traduções.

\footnotetext{
${ }^{7}$ Henri Meschonnic, Pour la poétique I, Paris, éd. Gallimard, 1982. O trabalho de Antoine Berman deve muito à imensa obra de Henri Meschonnic, da qual foi ouvinte e leitor constante. Mais tarde, orientada por Antoine, também eu o fui.
} 
É o caso, no século XX, de uma boa parte das literaturas latino-americanas, italiana e mesmo norte-americana (2007, p. 59).

Antoine dá aqui o exemplo do vernacular porteño (portègne, em sua tradução), traduzido em francês por "habitant de Buenos Aires".

No Brasil podemos citar o caso de grandes nomes de nossa literatura, de Guimarães Rosa a Graciliano Ramos, Dalton Trevisan, Luiz Alfredo Garcia-Roza e mesmo Clarice Lispector (quando em suas obras nos deparamos com expressões particulares de grupos sociais ou regionais, do sertão e do Nordeste, ao Sul do Brasil ou do Rio de Janeiro).

Paralelamente a essa tendência, encontra-se aquela que consiste em transformar as locuções e formas proverbiais presentes numa obra.

No caso da tradução de formas proverbiais, a tendência é "servir-se da equivalência" e assim "atentar contra o falar de uma obra".

Os equivalentes de uma locução ou de um provérbio não os substituem. Traduzir não é buscar equivalências. Ademais, querer substituí-las significa ignorar que existe em nós uma consciência-de-provérbio que perceberá imediatamente no novo provérbio, o irmão de um provérbio local (p. 60).

O apagamento da superposição de línguas

A superposição de línguas e linguagens variadas aparece em várias obras, onde coexistem dialetos, expressões, falares regionais. Mestiçagem.

Antoine Berman dá nesse ponto exemplos importantes, que vão de Joyce a Roa Bastos. Ele cita e trabalha sobre a tradução de vários autores latino-americanos. Dedicou um seminário à análise da tradução francesa de Grande Sertão: Veredas (traduzido como Diadorim), de Guimarães Rosa, mostrando nos detalhes o quanto esta havia transformado, deformado, empobrecido o texto de Guimarães Rosa, "em que o português clássico e os falares do Nordeste do Brasil se interpenetram" (2007, p. 61). (Eu diria "os falares do sertão" e não do Nordeste).

De Augusto Roa Bastos, cujo espanhol é modificado sintaticamente por duas outras línguas puramente orais, o quíchua e o guarani, Antoine Berman se pergunta, como traduzir e "preservar" em francês essa tensão entre as diferentes línguas (p. 61). 
Os exemplos são múltiplos. No Brasil, tantos quantos "brasis" existem. Tantas são as línguas faladas (escritas ou não) na América Latina, tantos os "espanhóis" quantos são os países da América hispanófona.

De Laura Esquivel (México) temos o exemplo de sua magistral Malinche, que, contando a seu modo a conquista do México por Hernan Cortês, e o papel que nela desempenhou sua tradutora e esposa, "La Malinche", constrói uma obra fulgurante, onde o mexicano se encontra completamente mesclado ao Nahuatl - azteca - e suas variações regionais.

Essa obra é extremamente importante no que toca também ao papel da tradução na história da colonização, destruição e construção dos povos da América Latina. Uma obra que pensa a tradução inscrita como questão em seu texto, em suas consequências políticas, culturais, humanas.

Outros tantos exemplos me vêm ao espírito para terminar essa introdução a uma leitura da obra de Antoine Berman, cuja sutileza convida a outras leituras, por tradutores e escritores, por outras gerações de leitores, inscritos no movimento da historicidade das obras.

Para terminar, e seguindo os traços da "analítica das traduções", reproduzo aqui alguns exemplos.

Prefácio do tradutor (Marc Chapiro) dos Irmãos Karamazov, de Dostoiévski, em francês (Lausanne: éd. Rencontre, 1968): ${ }^{8}$

\begin{abstract}
O peso original do estilo de Dostoiévski coloca ao tradutor um problema quase insolúvel. Teria sido impossível reproduzir suas frases emaranhadas, apesar da riqueza de seu conteúdo. [...] Uma outra dificuldade da tradução é inerente ao gênio da língua russa, que, como a maior parte das línguas jovens, é eminentemente sugestiva. Muitas coisas estão contidas na frase russa, sem serem expressamente formuladas. $\mathrm{O}$ francês, ao contrário, como toda língua evoluída, é essencialmente explícito. Para render as sugestões da frase russa, é frequentemente preciso completá-la.
\end{abstract}

A oposição "selvagem e civilizado"... não terá passado desapercebida ... assim se justifica a não-tradução...

\footnotetext{
${ }^{8}$ Citado por Henri Meschonnic, Pour la poétique II, Paris: éd. Gallimard, 1973, p. 317-318, e por Antoine Berman, op. cit, p. 69. Tradução brasileira, p. 49.
} 


\section{Trata-se da criação do homem e da mulher no livro do Gênesis. ${ }^{9}$}

21 Então YHVH Ehyeh Elohim fez cair um sono pesado sobre o homem, e este adormeceu; tomou-lhe, então, uma das costelas, e fechou a carne em seu lugar;

22 e da costela que Ehyeh Elohim lhe tomara, formou a mulher e a trouxe ao homem.

23 Então disse o homem: Esta é agora osso dos meus ossos, e carne da minha carne; ela será chamada mulher, porquanto do marido foi tomada.

\section{Comentário de Delphine Horvilleur (2013) ${ }^{10}$ :}

... a costela $\left({ }^{*}\right)$ coloca uma outra questão que merece exegese: por que a cisão só seria a de um osso lateral? Por que esse feminino separado, a Eva por vir, teria precisamente nascido dessa parte da anatomia? E se tudo isso não fosse senão um mal-entendido com repercussões gigantescas? E se se tratasse simplesmente de uma tradução errada?

$[\ldots]$ Política da tradução

A palavra hebraica utilizada no Gênesis e traduzida por "costela" na maior parte das edições bíblicas é Tzela. Ora, essa palavra, utilizada em outras passagens da Bíblia, é sempre traduzida por "ao lado" e não "costela" ( ${ }^{*}$ ). A tradução pode parecer anódina, mas ela tem repercussões pesadas. Num caso, a mulher "costela" é um objeto construído, um osso, isto é, uma estrutura parcial esculpida fora do corpo de um homem completo. Ela se encontra no limite de seu ser, elemento de apoio que toma vida, mas fica, por sua origem, dependente do corpo primeiro, masculino. No outro caso, a mulher "ao lado" é uma cisão de um ser original andrógino daí por diante dividido em dois. Ela é um outro sujeito, e não um objeto, saído do organismo primeiro com dois gêneros, da mesma forma que o homem. Nessa versão, os dois gêneros são, cada um deles, divididos, separados da entidade primeira e indivisa que eles constituíam.

A teorização da relação homem-mulher em nossa civilização foi largamente construída e nutrida ao longo dos séculos pela primeira tradução e não pela segunda: de um modelo feminino lateral costela e não ao lado de Adão, percebido como objeto parcial e derivado de um corpo completo e viril. Talvez tenha sido suficiente uma (má) tradução para que seja assim.

\footnotetext{
${ }^{9}$ Citação tirada de: As santas escrituras de Ehueh Adonai, trad. Francisco A.F. Macedo. O texto hebraico de publicação original é de domínio público (http://www.fourmilab.ch/etexts/www/hebrew/Bible).

${ }^{10}$ En tenue d'Ève. Féminin, pudeur et judaïsme, Paris: Grasset, 2013
} 
${ }^{*}$ ) côte em francês

Em francês as palavras são próximas (côte e coté), só um acento as diferencia, mas algo em sua polissemia as aproxima:

côte = costela (osso chato do tórax), osso lateral do corpo, litoral

coté $=$ lado

Diz-se "estar ao lado de alguém" = être à coté de quelqu'un.

Mas também: "andar lado a lado" = marcher côte à côte.

Nos dois casos trata-se então de estar "ao lado".

Último e mínimo exemplo: trata-se também de um erro sobre uma única letra, que compromete, no entanto, toda leitura do texto de Clarice Lispector, Perto do coração selvagem, na tradução francesa que realizei: Près $d u$ coeur sauvage (Paris: Ed. Des Femmes, 1998).

Contexto: a personagem Joana, após uma vida ordinária, apenas rompida por suas interrogações essenciais sobre a vida, a morte, a infância, o amor, libera-se do que a tinha encerrada no cotidiano e parte para uma viagem... em direção a uma liberdade desconhecida e desejada.

É o fim do livro. Texto em português:

E um dia virá, sim, um dia virá em mim a capacidade tão vermelha e afirmativa quanto clara e suave, um dia o que fizer será cegamente seguramente inconscientemente, pisando em mim, na minha verdade, tão integralmente lançada no que fizer que serei incapaz de falar, sobretudo um dia virá em que todo o meu movimento será criação, nascimento, eu romperei todos os nãos que existem dentro de mim... (grifo meu)

Tradução francesa publicada:

Et un jour viendra, oui, un jour viendra en moi la capacité aussi rouge et affirmative que claire et suave, un jour ce que je ferai sera aveuglement sûrement inconsciemment, marchant en moi, dans ma vérité, si intégralement lancée dans ce que je ferai que je serai incapable de parler, surtout un jour viendra où tout mon mouvement sera création, naissance, je briserai tous les noms qui existent à l'intérieur de moi... (grifo meu)

A tradução substituiu "nãos" (nons) por "nomes" (noms): que seja um erro de datilografia, uma casca, devido à proximidade entre o $\mathbf{m}$ e o $\mathbf{n}$, no 
teclado de minha velha Olympia, ou um erro de tipografia ou de leitura da editora no momento de imprimir o livro, pouco importa.

Importante é saber que o trabalho do tradutor é sempre um combate contra a tentação da não-tradução à obra em todo trabalho de tradução.

\section{Referências}

BERMAN, Antoine. La traduction et la lettre ou l'auberge du lointain. In: BERMAN, A.; GRANEL, G. ; JAULIN, A. ; MAILHOS, G. Les tours de Babel: essais sur la traduction. Paris: Trans-Europ-Repress, 1985.

BERMAN, Antoine. A prova do estrangeiro: cultura e tradução na Alemanha romântica. Tradução de Maria Emília Pereira Chanut. Bauru, SP: EDUSC, 2002.

BERMAN, Antoine. L'épreuve de l'étranger: culture et traduction dans l'Allemagne romantique. Paris: Gallimard, 2011.

BERMAN, Antoine. A tradução e a letra ou o albergue do longínquo. Tradução de Marie-Hélène Catherine Torres, Mauri Furlan, Andreia Guerini. Revisão de tradução: Luana Ferreira de Freitas, Marie-Hélène Catherine Torres, Mauri Furlan, Orlando Luiz de Araújo (texto em grego). $2^{\mathrm{a}}$ ed. Tubarão: Copiart; Florianópolis: PGET/UFSC, 2012. Disponível em: https://repositorio.ufsc.br/xmlui/handle/123456789/178888

MESCHONNIC, Henri. Pour la poétique I. Paris: éd. Gallimard, 1982.

\section{Resumo}

Para um novo conhecimento do pensamento sobre a tradução. O que é ou poderia ser uma "ética da tradução" das obras em prosa. A prosa também é poética. $\mathrm{O}$ pensamento da tradução segundo Antoine Berman tem por horizonte a "tradutologia": ética, poética, filosófica da tradução. Por uma nova maneira de traduzir que acolha a obra original estrangeira no seio da cultura e da língua de tradução (o Albergue do longínquo). Para isso, é necessária uma análise das traduções existentes e de suas falhas. Contra o dito "tradutor-traidor", contra a tradução etnocêntrica, adaptativa, levantase a obra de Antoine Berman.

Palavras-chave: Antoine Berman; Pensamento sobre a tradução; Tradutologia; Etnocentrismo; Análise de traduções; Ética da tradução ética 